\title{
Nontraumatic warfarin-related intrapulmonary hemorrhage presenting as a lung mass
}

\author{
Hiroyuki Tsuchida1*, Ryo Fujikawa' ${ }^{1}$, Hidenori Nakamura² and Toru Nakamura'
}

\begin{abstract}
Background: Although bleeding events are the major concern when using oral anticoagulants, intrathoracic hemorrhages due to warfarin are rare. Most cases in the literature have been related to trauma and have manifested as a hemothorax. Here we report a case of a nontraumatic hemorrhage within a pre-existing pulmonary cyst that presented as a lung mass during warfarin therapy.

Case presentation: A 75-year-old asymptomatic woman presented with a 10-cm-diameter mass on chest radiography that was not evident 6 months prior. She had been taking warfarin for paroxysmal atrial fibrillation and a transient ischemic attack. There was no history of chest trauma, warfarin overdosing, or any suspected interactions with other drugs such as nonsteroidal anti-inflammatory drugs or antibiotics. The prothrombin time/international normalized ratio(PT-INR) was prolonged at 4.73 and her hemoglobin level was $8.7 \mathrm{~g} / \mathrm{dl}$. Chest computed tomography(CT)revealed an air-fluid mass adjacent to the right upper and middle lobes with a pleural effusion. A CT scan obtained 15 years prior revealed a cyst at the corresponding site and the mass was diagnosed as a warfarin-related hemorrhage within the pre-existing pulmonary cyst. We performed a surgical resection of the cyst to prevent any worsening hemorrhage and subsequent infection. The postoperative course was uneventful and the patient was discharged on the 3rd postoperative day.

Conclusion: A warfarin-related thoracic hemorrhage, other than a hemothorax, could manifest as a pulmonary mass on radiography in patients with pre-existing pulmonary cysts. History taking especially of any anticoagulant medications and a precise assessment of the past images are crucial for a correct diagnosis. Once the intrapulmonary cystic hemorrhage becomes evident, prompt withdrawal with a reversal of warfarin and surgical resection are required to prevent a worsening hemorrhage and subsequent infection.
\end{abstract}

Keywords: Warfarin, Intrapulmonary hemorrhage, Anticoagulation, Bleeding events

\section{Background}

Although bleeding events are the major concerns of oral anticoagulant use, intrathoracic hemorrhages due to warfarin are rare with a frequency of $3 \%$ [1]. Most cases in the literature have been related to trauma and have manifested as a hemothorax. To the best of our knowledge, there have been no reports of intrapulmonary

\footnotetext{
*Correspondence: genbara2nhs@gmail.com

1 Department of General Thoracic Surgery, Seirei Hamamatsu General

Hospital, 2-12-12, Sumiyoshi, Naka-ku, Hamamatsu, Shizuoka 430-8558, Japan Full list of author information is available at the end of the article
}

hemorrhages associated with warfarin. Here we report a case of a nontraumatic hemorrhage within a pre-existing pulmonary cyst presenting as a lung mass during warfarin therapy.

\section{Case presentation}

A 75-year-old asymptomatic woman presented with a 10-cm-diameter mass on her chest radiograph, which was not evident 6 months prior (Fig. 1). She had been taking warfarin for paroxysmal atrial fibrillation and a transient ischemic attack for 6 years. There was no

\section{Springer Open}

(c) The Author(s). 2020 Open Access This article is licensed under a Creative Commons Attribution 4.0 International License, which permits use, sharing, adaptation, distribution and reproduction in any medium or format, as long as you give appropriate credit to the original author(s) and the source, provide a link to the Creative Commons licence, and indicate if changes were made. The images or other third party material in this article are included in the article's Creative Commons licence, unless indicated otherwise in a credit line to the material. If material is not included in the article's Creative Commons licence and your intended use is not permitted by statutory regulation or exceeds the permitted use, you will need to obtain permission directly from the copyright holder. To view a copy of this licence, visit http://creativecommons.org/licenses/by/4.0/. 


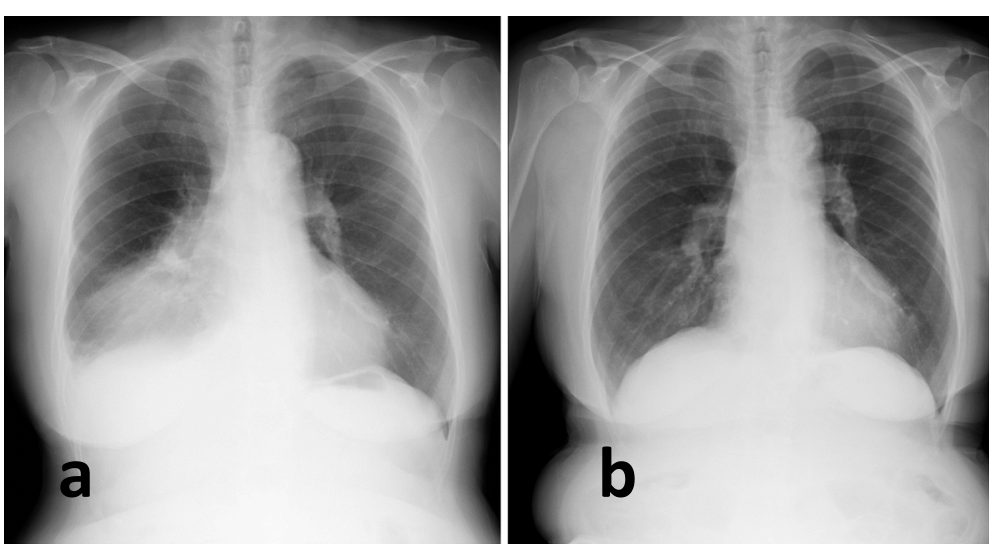

Fig. 1 A chest radiograph on admission revealed a mass (a) which was not evident 6 months prior (b)

history of chest trauma, warfarin overdosing, or suspected interactions with other drugs such as nonsteroidal anti-inflammatory drugs or antibiotics. She had no fever, leukocytosis, or elevated C-reactive protein. The prothrombin time/international normalized ratio (PTINR) was prolonged at 4.73 and her hemoglobin level was $8.7 \mathrm{~g} / \mathrm{dl}$. Chest computed tomography $(\mathrm{CT})$ revealed an air-fluid mass adjacent to the right upper and middle lobes with a pleural effusion (Fig. 2a). A CT scan obtained 15 years prior revealed a cyst at the corresponding site (Fig. 2b), and the mass was diagnosed as a warfarinrelated hemorrhage within the pre-existing pulmonary cyst. Immediately after the withdrawal of the warfarin and administration of vitamin $\mathrm{K}$, the PT-INR normalized to 0.96 without any further progression of the anemia or remarkable change in the mass and effusion. A surgical resection of the cyst to prevent a worsening hemorrhage and subsequent infection was planned.

Thoracoscopic view revealed the pulmonary cyst filled with a clot and $650 \mathrm{ml}$ of bloody effusion (Fig. 3). We performed wedge resection of the affected mass mainly arisen from the middle lobe. No intraoperative frozen section examination was performed. There were no other obvious bleeding points. The operation time was
$102 \mathrm{~min}$ and the blood loss was $5 \mathrm{ml}$. The pathological findings revealed an emphysematous bulla filled with a blood clot with an alveolar hemorrhage. The cause of the bleeding remained uncertain because there were no neoplastic lesions with any specific blood vessels involved in the resected specimen. The postoperative course was uneventful and the patient was discharged on the 3rd postoperative day. A direct oral anticoagulant (DOAC) was administered thereafter. She currently remains disease-free at 2 months after the operation.

\section{Comments}

Our case exhibited two important issues. The first was that an intrapulmonary hemorrhage, other than a hemothorax, could occur as an anticoagulant-related bleeding event. Warfarin is one of the leading causes of drugrelated adverse events [1-3], and its effect is influenced by several factors such as a genetic variation and drug interactions with a narrow therapeutic range by which bleeding events could occur. It could involve gastrointestinal, urinary tract, and intracranial bleeding, whereas thoracic hemorrhages are rare, with only a few cases having been reported to date [2, 4-7]. Most cases in the literature manifested as a hemothorax associated with

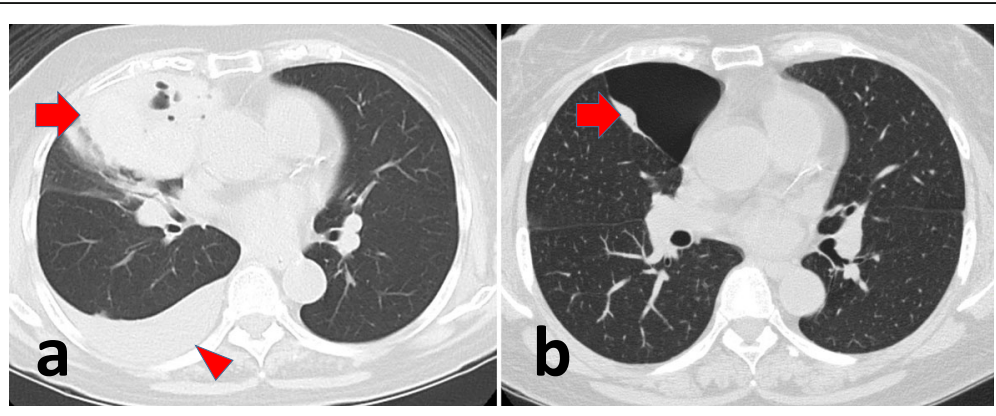

Fig. 2 a A chest CT on admission revealed an air-fluid mass (arrow) adjacent to the right upper and middle lobe with a pleural effusion (arrowhead). b A CT scan obtained 15 years prior revealed a cyst(arrow)at the corresponding site 


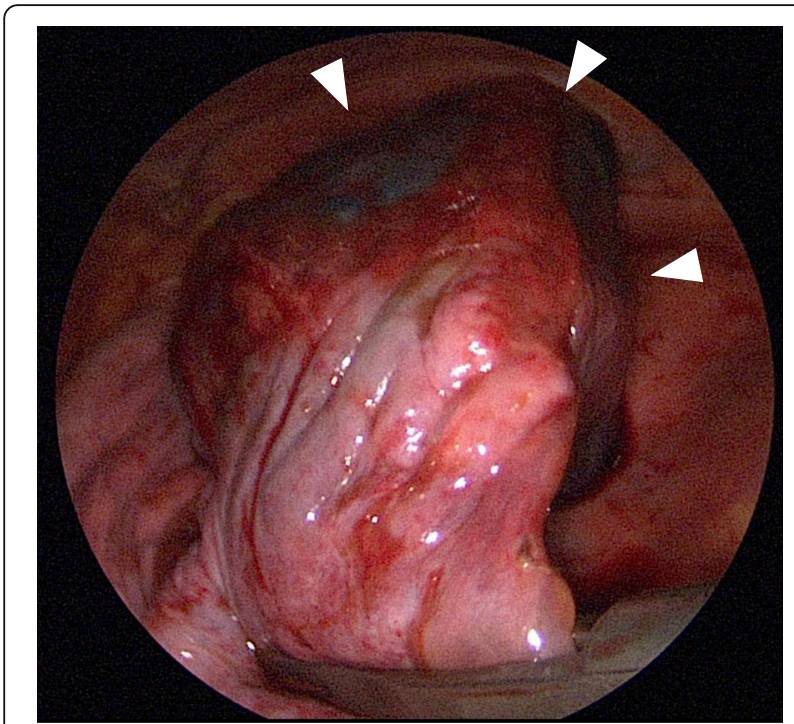

Fig. 3 A thoracoscopic view revealed a pulmonary cyst filled with a clot and bloody effusion (arrowheads)

trauma, and to the best of our knowledge, this is the first report of a nontraumatic intrapulmonary hemorrhage during warfarin therapy. The etiology of the sudden hemorrhage in our case was unclear and without a history of trauma or the concomitant use of any suspected drugs, which may have interacted with warfarin. An additional precise interview of the patient failed to identify any interpretable contributing factors such as a relevant diet.

The second point was that a hemorrhage inside a pulmonary cyst could manifest as a mass, without a diffuse opacity, in cases with a typical alveolar hemorrhage on radiography. While a neoplastic lesion was raised as a differential diagnosis during the initial workup, warfarin use with a prolonged PT-INR and the pulmonary cyst visualized on the CT scan 15 years prior made a diagnosis of a drug-related hemorrhage in the present case. We thoracic surgeons should be aware of the possibility that an intrapulmonary hemorrhage could manifest with such an atypical radiological finding in patients with preexisting pulmonary cysts.

Evacuation of a bloody effusion is essential for a thoracic hemorrhage mainly because the retained clot could cause subsequent empyema $[8,9]$. While an adequate tube thoracostomy might be sufficiently effective in most cases, a surgical debridement was required in the present case because the intrapulmonary hemorrhage was more significant than a hemothorax. With a prompt reversal of warfarin, the affected area was successfully resected and there have been no bleeding events even after the administration of DOACs to date.

\section{Conclusions}

Warfarin-related thoracic hemorrhages other than a hemothorax could manifest as a pulmonary mass on radiography in patients with a pre-existing pulmonary cyst. History taking especially for anticoagulant medications and a precise assessment of the past images are crucial for a correct diagnosis. Once an intrapulmonary cystic hemorrhage becomes evident, prompt withdrawal and reversal of warfarin and a surgical resection are required to prevent a worsening hemorrhage and subsequent infection.

\section{Abbreviations \\ PT-INR: Prothrombin time/international normalized ratio; CT: Computed tomography}

\section{Acknowledgements}

We thank Mr. John Martin for his proof-reading of the manuscript.

\section{Authors' contributions}

HT wrote this paper. The authors read and approved the final manuscript.

Funding

Not applicable.

\section{Availability of data and materials}

Not applicable.

Ethics approval and consent to participate

Not applicable.

\section{Consent for publication}

Written informed consent for the publication of the case details was obtained from our patient.

\section{Competing interests}

The authors declare that they have no competing interests.

\section{Author details}

${ }^{1}$ Department of General Thoracic Surgery, Seirei Hamamatsu General Hospital, 2-12-12, Sumiyoshi, Naka-ku, Hamamatsu, Shizuoka 430-8558, Japan. ${ }^{2}$ Department of Respiratory Medicine, Seirei Hamamatsu General Hospital, 2-12-12, Sumiyoshi, Naka-ku, Hamamatsu, Shizuoka 430-8558, Japan.

Received: 6 February 2020 Accepted: 26 March 2020

Published online: 10 April 2020

\section{References}

1. Landefeld CS, Beyth RJ. Anticoagulant-related bleeding: clinical epidemiology, prediction, and prevention. The American Journal of Medicine. 1993;95(3):315-28.

2. Hafner JW Jr, Belknap SM, Squillante MD, Bucheit KA. Adverse drug events in emergency department patients. Ann Emerg Med. 2002;39(3):258-67.

3. Budnitz DS, Pollock DA, Mendelsohn AB, Weidenbach KN, McDonald AK, Annest JL. Emergency department visits for outpatient adverse drug events: demonstration for a national surveillance system. Ann Emerg Med. 2005; 45(2):197-206.

4. Pirmohamed M, James S, Meakin S, Green C, Scott AK, Walley TJ, et al. Adverse drug reactions as cause of admission to hospital: prospective analysis of 18820 patients. BMJ. 2004;329(7456):15-9.

5. Azfar Ali H, Lippmann M, Mundathaje U, Khaleeq G. Spontaneous hemothorax: a comprehensive review. Chest. 2008;134(5):1056-65

6. Dogan NO, Pamukcu Gunaydin G, Tekin M, Cevik Y. Nontraumatic massive spontaneous hemothorax with concomitant warfarin use. Case Rep Emerg Med. 2013;2013:546024.

7. Singer AJ, Quinn A, Dasgupta N, Thode HC Jr. Management and outcomes of bleeding events in patients in the emergency department taking 
warfarin or a non-vitamin $\mathrm{K}$ antagonist oral anticoagulant. J Emerg Med. 2017;52(1):1-7 e1.

8. Altiok E, Marx N. Oral anticoagulation. Dtsch Arztebl Int. 2018;115(46): 776-83.

9. Stewart RM, Corneille MG. Common complications following thoracic trauma: their prevention and treatment. Semin Thorac Cardiovasc Surg. 2008;20(1):69-71.

\section{Publisher's Note}

Springer Nature remains neutral with regard to jurisdictional claims in published maps and institutional affiliations.

\section{Submit your manuscript to a SpringerOpen ${ }^{\mathcal{O}}$} journal and benefit from:

- Convenient online submission

- Rigorous peer review

- Open access: articles freely available online

- High visibility within the field

- Retaining the copyright to your article

Submit your next manuscript at $\boldsymbol{\nabla}$ springeropen.com 